\title{
接触レーザー照射用導光プローブに関する研究
}

Studies on the application of the newly developed laser microprobes for the contract laser endoscopy

\author{
○恒川 洋、 中田耕 - * 金山和広、* 古沢 敦、 印牧直人、 \\ 堀田素子、* 西田元彦、* 大矢 博、 森瀬公友、* 飯塚昭男、*

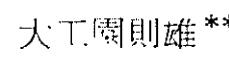 \\ H. Tsunekawa*, K. Nakada, K. Kanayama*, A. Furusawa*, \\ N. Kanemaki, M. Hotta,, M. Nishida*, H. Oya*, K. Morise,* \\ A. Iizuka, N. Daikuzono***

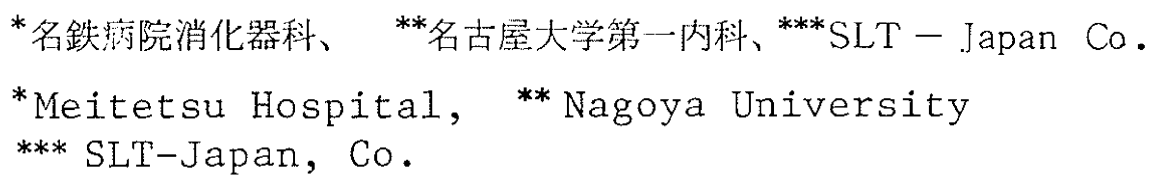

To overcome disadvantages with an optical quartz fiber used in laser endoscopy, five types microprobes made of artificial sapphire $\left(\mathrm{Al}_{2} \mathrm{O}_{3}\right)$, i.e., tip type probe, rod type probe, round tip type probe, cutter type probe and high divergent rod type probe were developed. Assessing the efficacy and safety of these probes, animal experiments were performed with the Nd-YAG laser during laparotomy. The results obtained revealed that various contact irradiations using

laser microprobes were more safe and effective than the non-contact irradiations. On the basis of this results, we attempted a wide variety of clinical applications. The results suggest that the tip type probe is applicable to the treatment of protruded tumors of G.I. tract and hemostasis of G.I. bleeding, and the rod type probe and the round tip type probe are of benefit to the treatment of G.I. stensis. Furthermore, we are currently performing experimental and clinical studies on endoscopic local hyperthermia using a high divergent rod type probe and low power laser irradiation for depressed cancer.

\section{I 諸言}

近年のレーザー内視鏡の急速な進歩は石英によ る flexibleな導光ファイバーの開発によるところ が大である。しかし臨床応用が重㸚られると共に 石英のもつ多くの問題点が明らかとなった。すな わち、組織に接触照射した場合、容易に破損する こと、このため照射方法が非接触法にならざるを 得ないこと。従って照射距離の一定化が困難とな ることなどである。著者らは導光ファイバー（石 英）と照射方法（非接触法）の問題点を一挙に解
決し、さらに新しい接触レーザー治療法の確立を 目的として新しい素材（ニューセラミックス）を 用いて五種類の接触可能なレーザー内視鏡用導光 プローブ ( $\mathrm{tip}$ 型、 rod 型、round tip 型、c11tter 型、高搪散 rod 型)を開発した。これらを従 来の石英ファイバーの先端に着脱可能な金属コネ クターにて装着し使用しだ。尚、ファイバー、プ ローブの泠却法を従来のガスジエット方式から水 冷方式に変更するためファイバーを改造した。こ れらの導光プロ -..ブの安全性と有效性に関してNd 
ーYAGレーザーを用いた基礎的および臨床的検討 を行ったので報告する。

II 接触型導光プローブの概要

プローブの素材は酸化アルミニウム $\left(\mathrm{A}_{2} \mathrm{O}_{3} \mathrm{O}_{3}\right)$ の溶融体を原料としたニュ一セラミックスである。 ニューセラミックスは石英に比べ酎熱温度、強度、 硬度が高く熱伝導率が低い上、組織が付着しにく い特性があり接触型導光体として優れている1)。 図 1 に五種類のプロ--ブの形状、使用目的、レ一 ザー射出角度 $(\theta)$ を図示した。

図 1

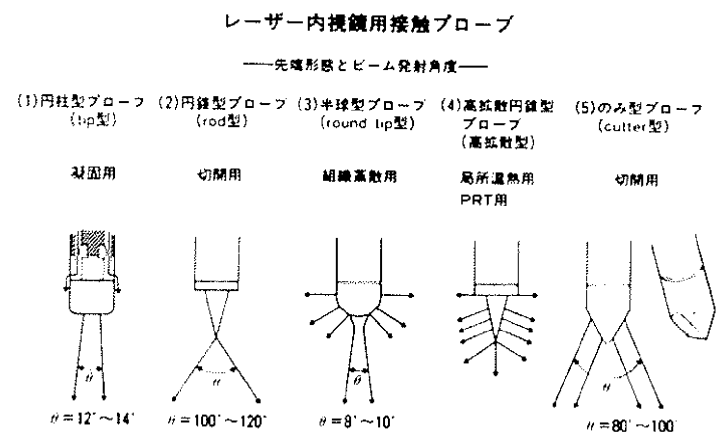

III レーザー発生装置

$\mathrm{Nd}-\mathrm{YAG} レ$ レ・゙゙ー発生装置としてM.B.B 社製 Modilas およびMolectron 社製Model 8000を使用 した。

\section{N 基礎的検討}

1）実験対象および方法

t ip 型と rod 型の実験には成犬 8 頭、round tip 型、cutter 型は家鬼 2 羽を用いネンブタ -... ル麻酔後、開腹下に胃粘膜にプローブを接触し出 力、時間を変えてパルス照射を行った。照射後、 胃全摘し胃粘膜および胃壁の变化を肉眼的、組織 学的に検討した。高拡散 rod 型の実験には担癌マ ウス (Lewis lung carcinomaを皮下移殖した $\mathrm{BDF}_{1}$ マウス） 20 匹を用いた。図 2 に示すレー ザ一局所温熱療法システムを作製し、高拡散型プ ロー-ブと共に温度センサーを癌巣内に穿刺しプロ 一ブ穿刺部温度を $43^{\circ} \sim 60^{\circ} \mathrm{C}$ に維持するよう に経時的にモニターしながら低出力の連続照射を 行った。

\section{図 2}

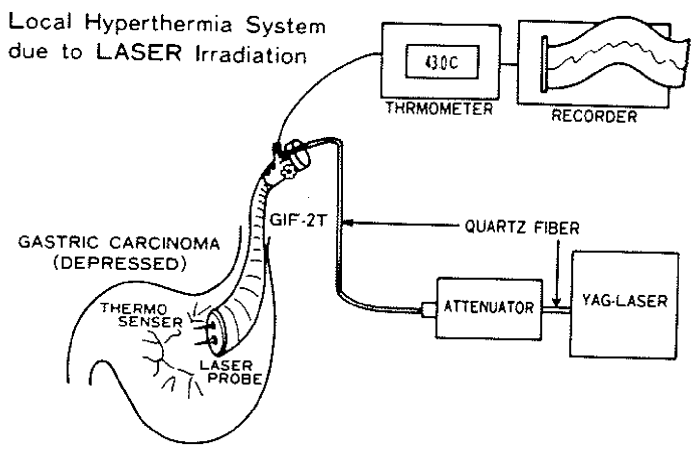

図 3

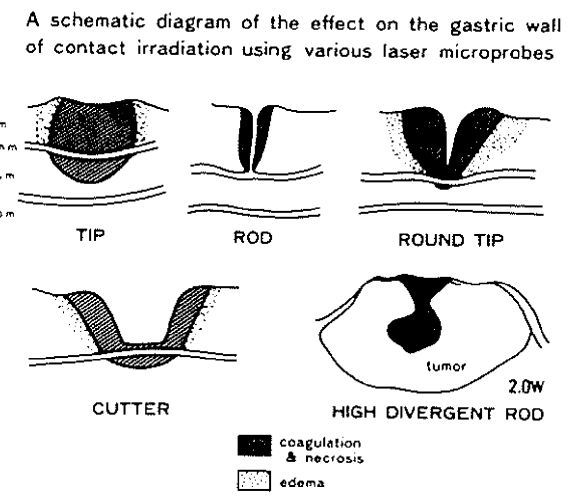

2）実験結果

図 3 に各種プローブによる照射部位の割面の組 織学的所見の特徴を示す。tip 型では粘膜上皮の 微かな陥山、浮腫之粘膜固有層、粘膜下層に挔が る類円形の凝固、壊死層を認めた。rod 型、round tip 型、cutter 型ではいづれもプローブの形状 に類似した特徵ある組織蒸散による組織欠損を形 成したが、round tip 型、cutter 型で欠損部の 周囲に強い凝固、溒死、浮腫層を認めたのに比べ rod 型では極めて弱い变化しか認められなかった 点、特徵的であった。次に高抎散型による温熱実 験では、プローブ穿刺部温度を $43^{\circ}$ 以上 $60^{\circ} \mathrm{C}$ 以 内に維持するにはファイバー先端出力 $2.0 \mathrm{~W}$ (プ ローブ先端 $1.0 \mathrm{~W}$ ) の連続照射が最適であった。 温熱照射後の組織変化は $2.0 \mathrm{~W}(1.0 \mathrm{~W})$ と 4.0 $\mathrm{W}(2.0 \mathrm{~W})$ 以上では異なり、 $2.0 \mathrm{~W}$ では 5 分間 連続照射後も組織の欠損がなかったのに対し 4.0 W以上ではプローブ穿刺部に楔状の欠損が形成さ れた。以上より組織学的にも $2.0 \mathrm{~W}$ 連続照射の温 熱効果の有効性が証明された。 
V 臨床的検討

\section{1）対象拉よび方法}

基礎実験の結果に基づき各プロ・ブの安全かつ 效果的な照射条件を設定し臨床応用を行った。対 象は t ip 型による 62 例、 rod 型 6 例、round t ip 型 11 例 cutter 型 1 例、高拡散型 7 例で ある。内訳は tip 型が早期胃癌 8 例、胃異型上皮 8 例、消化管出血 11 例、胃ポリープ 35 例であ り、 $\operatorname{rod}$ 型が消化管狭窄 4 例、胃粘膜下腫痬生検 2 例、round tip 型が消化管狭窄 9 例と遗残総胆 管結石 2 例、cutter 型が消化管狭窄 1 例、高㹡散 型が早期胃癌 7 例であった。

2）治療成績

a）早期胃癌に対する治療成績

t ip 型による早期胃癌に対する照射効果を表 1 に示す。ファイバー先端出力 $24 \sim 28 \mathrm{~W}$ (プロ …ブ先端1 6 〜 18W）1秒間を照射条件とした。 症例 $1 \sim 4,8$ は何らかの理由による手術不能例で 局所根治を目的とした。接触照射 $1 \sim 2$ 週後比生 検施行し生検陽性の場合には陰性化するまで追加 照射した。5例すべて数回の照射にて生検陰性と なった。症例 $5 〜 7$ は術前照射例で切除盟による 検討で 3 例中 2 例にレーザ一潰痬下あるいは謴掦 の辺縁の一部に癌の残存を認めた。いづれも陷山 性癌であった。

表 1

\begin{tabular}{|c|c|c|c|c|c|c|}
\hline Cases & $A_{\mathrm{E}}$ & Sex & Type & Location & Dose & Eflect \\
\hline 1. H.K. & 80 & 8 & 1 & $\begin{array}{l}\text { Post. } \\
\text { Body }\end{array}$ & $3539 \mathrm{~J}$ & Biopsy (-) \\
\hline 2. S.Y. & 74 & $\hat{f}$ & $11 \mathrm{c}$ & $\begin{array}{l}\text { Less. Curva. } \\
\text { Angulus }\end{array}$ & $1268 \mathrm{~J}$ & Biopsy (-) \\
\hline 3. Y.T. & 86 & $\hat{\hat{3}}$ & IIc & $\begin{array}{l}\text { Less. Curva. } \\
\text { Anguius }\end{array}$ & $3262 \mathrm{~J}$ & Biopsy (-) \\
\hline 4. Y.T. & 86 & $\vdots$ & $11 a+11 c$ & $\begin{array}{l}\text { Post: } \\
\text { Antrum }\end{array}$ & $323 \mathrm{~J}$ & Biopsy(-) \\
\hline 5. Y.S & 55 & $\therefore$ & \#c & $\begin{array}{l}\text { Post } \\
\text { Body }\end{array}$ & $440 \mathrm{~J}$ & Operation (-) \\
\hline 6. M.A. & 40 & $\therefore$ & II $\mathrm{C}$ & $\begin{array}{l}\text { Post } \\
\text { Antrum }\end{array}$ & $2066 \mathrm{~J}$ & Operation( $(+)$ \\
\hline 7. T.O. & 71 & $\hat{\mathrm{a}}$ & $\pi 1 a+\| c$ & $\begin{array}{l}\text { Ant. } \\
\text { Antrum }\end{array}$ & $941 \mathrm{v}$ & Operation(t) \\
\hline 8. M.Y & 72 & $\therefore$ & 1 & $\begin{array}{l}\text { Ant. } \\
\text { Body }\end{array}$ & $315 \mathrm{~J}$ & Siopsy(-) \\
\hline
\end{tabular}

b）胃異型上皮 (ATP) および胃ポリーープに対す る治療成績

tip 型を用い㥜A T P 8 例に対し $25 \sim 28 \mathrm{~W}$ 1 秒間のパルス照射学行ったところ、いづれも 1 〜3 回の照射にて病変は脱落消失しレーザ-ー臔瘳
を形成後、数週で㾗痕治療した。次に山田 I.II 型 胃ポリープ 35 例に $25 \sim 28 \mathrm{~W} 、 1$ 秒間照射を 行い、全例に $1 \sim 3$ 回で病変部の完全脱落と潰瘍 形成を認めた。

\section{表 2}

\begin{tabular}{|c|c|c|c|c|c|}
\hline Cases & Age & Sex & Bleeding Source & Dose & Effect \\
\hline 1. H.M. & 44 & 3 & Gastric ulcer & $448 \mathrm{~J}$ & Hemostasis \\
\hline N. 1. & 80 & 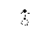 & Colon cancer & $431 \mathrm{~J}$ & Hemostasis \\
\hline 3. K.K. & 70 & $B$ & Gastric ulcer & $404 \mathrm{~J}$ & Hemostasis \\
\hline 4. K.H. & 76 & s. & Gastric cancer & $598 \mathrm{~J}$ & Hemostasis \\
\hline 5. R.O. & 40 & 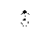 & Gastric ulcer & $92 \mathrm{~J}$ & Hemostasis \\
\hline 6. K. 1 & 56 & 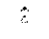 & Ischemic duodenitis & $203 \mathrm{~J}$ & Hemostasis \\
\hline 7. M.I. & 43 & 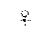 & Gastric ufcer & $105 \mathrm{~J}$ & Hemostasis \\
\hline 8. S.F. & 48 & $\vdots$ & Gastric ulcer & $172 \mathrm{~J}$ & Hemostasis \\
\hline 9. K.H. & 50 & s & Gastric ulcer & $189 \mathrm{~J}$ & $\begin{array}{l}\text { Homostasis } \\
\text { Robloeding }\end{array}$ \\
\hline 10. Y.T. & 86 & $\therefore$ & Gastric cancer & $336 \mathrm{~J}$ & Hemostasis \\
\hline 11. M.Y. & 59 & 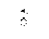 & Duodenal ulcer & $128 \mathrm{~J}$ & Hemostasis \\
\hline
\end{tabular}

c）消化管出血に対する治療成績（表 2)

種々の消化管出血 11 例に対し $\mathrm{t}$ ip 型 $28 \mathrm{~W}$ 、 $1.0 \sim 1.5$ 秒間照射を行った（表 2 ）。この結果 10 例に止血が得られたが症例 9 では琴日再出血 をきたした。症例 11 は動脈性出航で止血不能で あった。尚、殆んどの症例で出血は静脈性もしく は毛細管性で、軽度から中等度の出血であった。

表 3

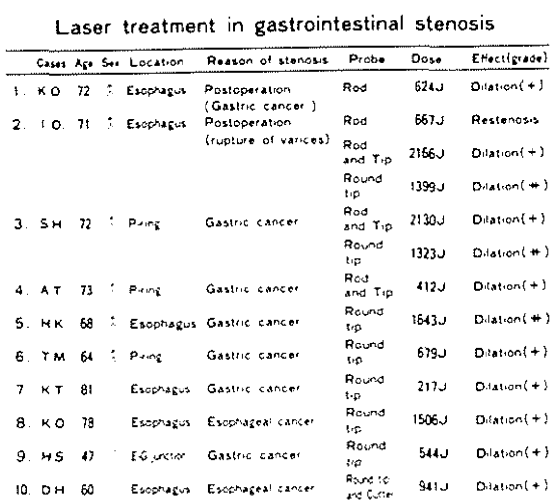

d）消化管狭窄に対する治療成績（表 3）

表 3 に示す上5に最初はrod 型単独で狭窄解除 を試みたが、易出血性、再狭窟など問題が多いた め rod 型と tip 型の併用照射が行われ狭窄部の開 大が得られた。しかし併用照射は二つのプローブ を交互に使用するため操作が煩雑であり、組織蒸 散と凝固を同時に行うプローブとして round tip 型が開発された。round t i p 型は良性、癌 性狭窄いつ㞦にも効果的で $15 \mathrm{~W}(10 \mathrm{~W}) 1$ 秒 
間照射で全例提食可能となった。尚、症例 10 で はcutter型を併用し、より大きな効果を上げて いる。

e）早期胃癌に刘する局所温熱療法成績 (表4) 高拡散型を用いて皮腐癌 1 例、早期胃癌 7 例 （表 4）に局所温熱祭法を行った。尚、皮䖉癌と 症例 1 ・2 はpilot studyの症例である。皮席癌 は ${ }^{60} \mathrm{C}_{0}$ 照射との併用によりファイバ-先端出力 $2.0 \mathrm{~W}$ (プロ ...ブ先端 $1.0 \mathrm{~W}$ ) 3 分間照射 2 回で 癌巣部の著しい繀少を文た。症例 1 ・2 には 2.0 $\sim 3.0 \mathrm{~W}(1.0 \sim 1.5 \mathrm{~W})$ 約 5 分間の術前試験照射 を行い切除胃にて照射効果を検討した。この結果 症例 1 ではレーザー潰㿇の一部に微かな癌の残存 を認めたが、症例 2 では広範な Ib + II cの一部に 試験照射したところレーザ-.潰痬形成部分には癌 宩を認めなかった。これらより非接触照射および tip 型による接触照射に比べ少ない照射量にてよ り安全かつ効果的に治療を行いらる可能性が示唆 された。そこで術前照射 2 例、手術不能例 3 例に $2.0 \sim 3.0 \mathrm{~W}(1.0 \sim 1.5 \mathrm{~W}) 3 \sim 10$ 分間の連 続照射を施行した。手術例では癌の微かな残存を 認めたが、症例 7 では生検陰性となった。症例 5 6 は現在、継続治療中である。

\section{VI 考按}

著者らは石英ファイバーのもつ種々な問題点を 解決するためめにニーセラミックスを素材として 接触レーザー照射用導光プロー-ブを開発し水冷式 の改造ファイバーに装着して安全性と有効性に関 する基礎的検討を行った。この結果従来の非接触 法に比べ安全性も高く少ないTotal energy で 確実な照射効果を得たので種々の臨床応用を行っ た。 tip 型による隆起型早期胃癌、A T P、ポリ 一プ、消化管出血に対する治療効果は極めて良好 であったが、陷凹型早期胃癌では $33 \%$ 癌の残 存を認めた。この成績は非接触照射による治療成 績2水類似しており陷凹性癌に対する.レーザー治 療の困難さを再認識させられた。陥凹性癌におけ る不十分な成績の理由として、術前の癌深達度、 浸潤範团の把握が不十分であったことに加之、穿 孔などの合作症を恐れるあまり十分な照射ができ
なかったことも否めない事実である。これはレー ザー一光の強いエネルギーを利用した現在の組織凝 固、蒸散を中心とする“焼く”照射方法の限界を 示すものと考えられた。そこで著者らは陷凹性癌 に対するより安全かつ効果的な新しい照射法とし てレーザーの温熱効果を利用した“温める”方法 すなわち局所癌温熱療法システムを開発し、高拡 散型プローブを試作して担癌マウスによる基礎実 験を行ったっっこの結果、 $2.0 \mathrm{~W}(1.0 \mathrm{~W})$ 連続照 射を最適の温熱条件之考光、現在臨床治験中であ る。次に rod 型単独あるいはrod型之 tip 型併用 による消化管狭窄解除は易出血性、操作の煩雑さ など欠点を有するため新たに round tip 型と cutter 型を開発した。round tip型は良性、癌 性狭窄に対し出血もなく確実に狭窄を解除した。 以上、五種類の導光プローブを用いた接触レーザ 一照射は治療目的に応じてプローブ選択可能であ り、安全かつ確実な照射効果が得られるため非接 触法に代わる新しいレーザ一照射法として期待で きる。

\section{表 4}

\section{Laser local hyperthermia in gastric cancer}

\begin{tabular}{|c|c|c|c|c|c|c|c|c|c|}
\hline & Cases & Agge & Sex & Type & Location & Power $(W)$. & Time (sec) & Dose & Effect \\
\hline 1. & T.K. & 38 & & $\| \mathrm{lc}$ & Angulus & $2.0 \sim 3.0$ & 320 & $484 \mathrm{~J}$ & Operation $(t)$ \\
\hline 2. & $Y, Y$. & 63 & : & $\|H b+\| c$ & $\begin{array}{l}\text { Angulus } \\
\sim \text { Body }\end{array}$ & $2.0 \sim 3.0$ & 335 & $437 \mathrm{~J}$ & $\operatorname{on}(t)$ \\
\hline 3. & T.K. & 53 & $:$ & $\|c+\|$ & Antrum & 2.0 & 536 & $536 \mathrm{~J}$ & Operationit) \\
\hline 4. & K.N. & 53 & : & $\| \mathrm{lc}$ & Body & 2.0 & 188 & 188. & Operationit 1 \\
\hline 5. & Y.T. & 86 & : & $\| c$ & $\begin{array}{l}\text { Angulus } \\
\sim \text { Body }\end{array}$ & 2.0 & 630 & 630. & Biopsy $(+)$ \\
\hline 6. & Y.T. & 83 & $:$ & Ilc & $\begin{array}{l}\text { Angulus } \\
\sim \text { Body }\end{array}$ & $2.0 \sim 2.5$ & 525 & 545 & Biopsy $(+)$ \\
\hline 7 & T.M. & 56 & $\therefore$ & Ho & Angulus & $2.0 \sim 3.0$ & 420 & 555 & Biopsy (-) \\
\hline
\end{tabular}

\section{文 献}

1) N. Daikuzono, S.N.Joffe : Medical Instrumentation, 15: 21, 1985.

2) 飯塚昭男、佰川 洋他 : Gastroenterological Endoscopy, 26:576, 1984 . 